\title{
Impact of vertical and horizontal advection on nutrient distribution in the southeast Pacific
}

\author{
Bàrbara Barceló-Llull ${ }^{1}$, Evan Mason ${ }^{2}$, Arthur Capet $^{3}$, and Ananda Pascual ${ }^{2}$ \\ ${ }^{1}$ Universidad de Las Palmas de Gran Canaria, ULPGC, Las Palmas de Gran Canaria, Spain \\ ${ }^{2}$ Institut Mediterrani d'Estudis Avançats, IMEDEA (CSIC-UIB), Mallorca, Spain \\ ${ }^{3} \mathrm{CNR}$, OGS, Trieste, Italy
}

Correspondence to: Bàrbara Barceló-Llull (b.barcelo.llull@gmail.com)

Received: 13 July 2015 - Published in Ocean Sci. Discuss.: 29 September 2015

Revised: 18 July 2016 - Accepted: 8 August 2016 - Published: 25 August 2016

\begin{abstract}
An innovative approach is used to analyze the impact of vertical velocities associated with quasi-geostrophic (QG) dynamics on the redistribution and uptake of nitrate in the southeast Pacific (SEP). A total of 12 years of vertical and horizontal currents are derived from an observationbased estimate of the ocean state. Horizontal velocities are obtained through the application of thermal wind balance to weekly temperature and salinity fields. Vertical velocities are estimated by integration of the QG omega equation. Seasonal variability of the synthetic vertical velocity and kinetic energy associated with the horizontal currents is coincident, with peaks in austral summer (November-December) in accord with published observations. The impact of vertical velocity on SEP nitrate uptake rates is assessed by using two Lagrangian particle tracking experiments that differ according to vertical forcing ( $\omega=\omega_{\mathrm{QG}}$ vs. $\left.\omega=0\right)$. From identical initial distributions of nitrate-tagged particles, the Lagrangian results show that vertical motions induce local increases in nitrate uptake reaching up to $30 \%$. Such increases occur in low uptake regions with high mesoscale activity. Despite being weaker than horizontal currents by a factor of up to $10^{-4}$, vertical velocity associated with mesoscale activity is demonstrated to make an important contribution to nitrate uptake, hence productivity, in low uptake regions.
\end{abstract}

\section{Introduction}

Mesoscale dynamics make an important contribution to biogeochemical cycles through the redistribution of nutrients and passive marine organisms by both horizontal advection and vertical exchange. Vertical motion plays a key role in the exchange of heat, salt and biogeochemical tracers between the surface and deep ocean. In coastal upwellings, frontal areas and mesoscale eddies, the vertical velocity has fundamental importance and can significantly contribute to nutrient supply in the euphotic zone (Mahadevan, 2014).

Previous remote sensing studies (Chelton et al., 2011a) have revealed that chlorophyll $a$ distributions within mesoscale eddies are characterized by dipole-like patterns, with extreme values found at the eddy peripheries. Chelton et al. (2011a) proposed that eddy horizontal advection could explain these distributions. On the other hand, the importance of vertical exchange for phytoplankton growth and chlorophyll $a$ distributions in mesoscale oceanic eddies has been attributed to various mechanisms such as eddy pumping, eddy-induced Ekman pumping or vortex Rossby waves (McGillicuddy et al., 1998; Siegel et al., 1999; Mahadevan et al., 2012; Martin and Richards, 2001; McGillicuddy et al., 2007; Benítez-Barrios et al., 2011; Buongiorno Nardelli, 2013; Gaube et al., 2013, 2015).

In this context, we aim to estimate the importance of horizontal and vertical mesoscale motions on nutrient redistribution through the application of quasi-geostrophic (QG) theory to an observation-based product (Buongiorno Nardelli et al., 2012; Pascual et al., 2015). In particular, we aim to investigate the influence of derived horizontal and vertical ve- 
locities on ocean nitrate uptake in the southeast Pacific (SEP) through the use of a Lagrangian particle-tracking code.

The remote southeast Pacific is the least sampled oceanic region in the world ocean, in terms of both hydrography and biogeochemical structure (Ras et al., 2008). Synoptic observations from satellites provide crucial knowledge about such regions, despite their limitation to surface fields (Ducet et al., 2000; Dibarboure et al., 2011). The now-mature Argo program is a source of supplementary subsurface hydrographic data (temperature and salinity) in the form of discrete vertical profiles over a global, but sparse, grid. The ARMOR3D estimate of the ocean state (Guinehut et al., 2012) is an innovative product where remote sensing observations (sea surface temperature and sea level anomalies) are merged with in situ Argo temperature and salinity profiles. The resulting multivariate observation-based data set is freely available (see Section 3).

The southeast Pacific has a variety of different trophic regimes (Ras et al., 2008) such as the upwelling zone near the Peru-Chile coast that is rich in nutrients and has high chlorophyll $a$ concentrations, and the area associated with the central part of the South Pacific Gyre, which is the most oligotrophic area in the global ocean (Morel et al., 2010). Mesoscale effects on chlorophyll $a$ production can be considered to differ between regions with different dynamical characteristics. Lathuiliere et al. (2011) demonstrate that, while mesoscale activity in upwelling regions leads primarily to offshore export of phytoplankton, in the oligotrophic gyres mesoscale processes promote vertical advection of nutrients into the euphotic layer, thereby stimulating primary production. The present work is focused on the same area analyzed by Chelton et al. (2011a), the offshore southeast Pacific (white box in Fig. 1), where nutrient input by mesoscale vertical exchange is considered to play a lead role in primary production (Lathuiliere et al., 2011).

Figure 1 shows the time-averaged eddy kinetic energy (EKE) at the surface computed from daily AVISO (DT14, Capet et al. (2014)) sea level anomalies. The EKE in the South Pacific Gyre has lower values in comparison with more active regions such as the Gulf Stream or Agulhas Current (Pascual et al., 2006; Imawaki et al., 2013). However, this gyre also includes a region with relatively high EKE values corresponding to the midwest South Pacific. Qiu and Chen (2004) and Qiu et al. (2008) attribute the high EKE values found in this region to baroclinic instability of the eastward-flowing surface Subtropical Countercurrent (STCC) and the westward-flowing South Equatorial Current (SEC). Although the SEC is a surface current near the equator, it has a subsurface component that Qiu and Chen (2004) observed to as far south as $30^{\circ} \mathrm{S}$, where it underlies the STCC (see Fig. 3 of Qiu and Chen (2004)). Moreover, they also find that in this region seasonal EKE modulation is related to the seasonal intensification/decay of the STCCSEC baroclinic instability, with a maximum in NovemberDecember. In the same way, the gyre has another region with relatively high EKE values at its northwest corner. In contrast to the STCC-SEC system, Qiu and Chen (2004) attribute these high values to barotropic instabilities between the eastward South Equatorial Countercurrent (SECC) and its bordering westward SEC. The SECC-SEC system also presents seasonal EKE modulation, but with maxima in April because the SECC-SEC horizontal shear seasonality is dominated by seasonal changes in the strength of the SECC. The two systems analyzed by Qiu and Chen (2004) additionally show interannual EKE variability.

Figure 1 shows high EKE values off the Peru-Chile coast which is characterized by an important coastal upwelling and the consequent generation of mesoscale eddies and filaments (Brown et al., 2008; Brink and Robinson, 2005; Strub et al., 2013). The region of study (white box in Fig. 1) is characterized by relatively low EKE, with higher EKE values in the southwest corner that are related to the STCC-SEC system and, in the eastern section, to coastal upwelling eddy generation. However, the SEP has important eddy activity due, in part, to eddy formation in the Peru-Chile coastal upwelling (Chelton et al., 2011a) .

A brief description of the synthetic temperature and salinity fields and biogeochemical data is given in Sect. 2. Section 3 describes the methodology used to diagnose the quasigeostrophic vertical velocity, together with a description of the Lagrangian particle-tracking code utilized for the nitrate uptake simulation. In Sect. 4 the results of the vertical velocity and kinetic energy analysis as well as the results of the Lagrangian simulations are discussed. Section 5 summarizes and concludes the results.

\section{Data}

We use the ARMOR3D observation-based product which is based on the merging of gridded satellite sea level anomaly (SLA) and sea surface temperature (SST) remote sensing observations with in situ vertical profiles of temperature and salinity to provide a global 3-D data set of temperature and salinity (Guinehut et al., 2012). The data are computed on a $1 / 3^{\circ}$ Mercator horizontal grid with weekly temporal resolution covering the period 1998-2009, over 24 vertical levels from the surface to $1500 \mathrm{~m}$ depth. A validation of ARMOR3D is presented by Mulet et al. (2012) who use a consistent data set from a model reanalysis.

Auxiliary data are used to evaluate the impact of vertical and horizontal velocities on SEP nitrate uptake rates. Here we use climatological nitrate data from WOAPISCES (Penven et al., 2008). Nitrate data are chosen because their large vertical gradient over the mixed layer (Fig. $2 b$ and c) highlights the contribution of vertical velocity which is characterized by smaller values than horizontal currents, but is expected to play an important role in the introduction of nutrients into the euphotic layer. Figure 2a shows the horizontal nitrate distribution at $200 \mathrm{~m}$ depth from WOAPISCES. High 


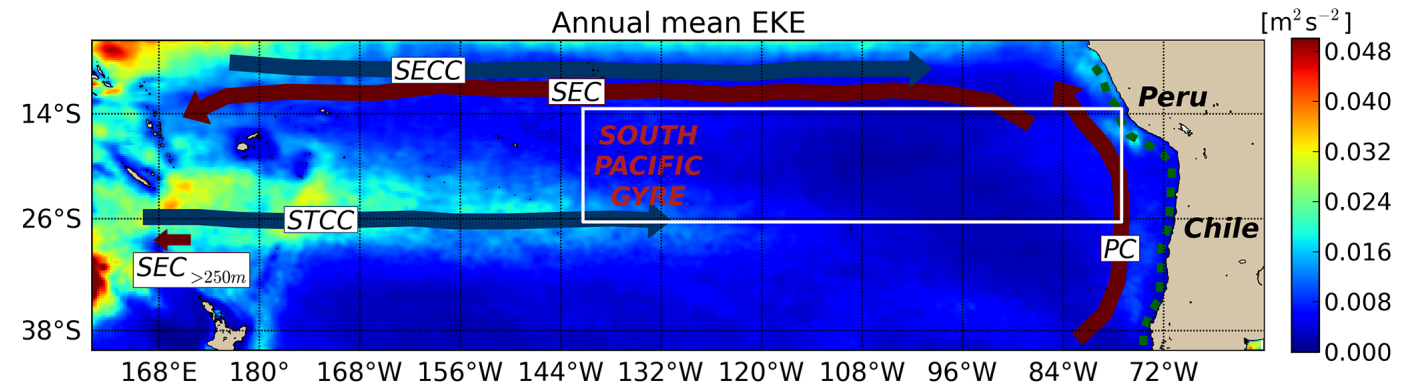

Figure 1. Map of the southeast Pacific. Colors show annual mean eddy kinetic energy (EKE) computed from daily AVISO (DT14, Capet et al., 2014) sea level anomaly data for the period 1993-2013. The white box shows the limits of the area of study. Key: SEC, South Equatorial Current; SECC, South Equatorial Countercurrent; STCC, Subtropical Countercurrent; PC, Peru Current. Green dashed line is the coastal upwelling. The small arrow indicates the poleward extent of the subsurface component of the SEC as observed by Qiu and Chen (2004) between 12 and $30^{\circ} \mathrm{S}$ at $170^{\circ} \mathrm{E}$.

(a) Nitrates at $200 \mathrm{~m}$

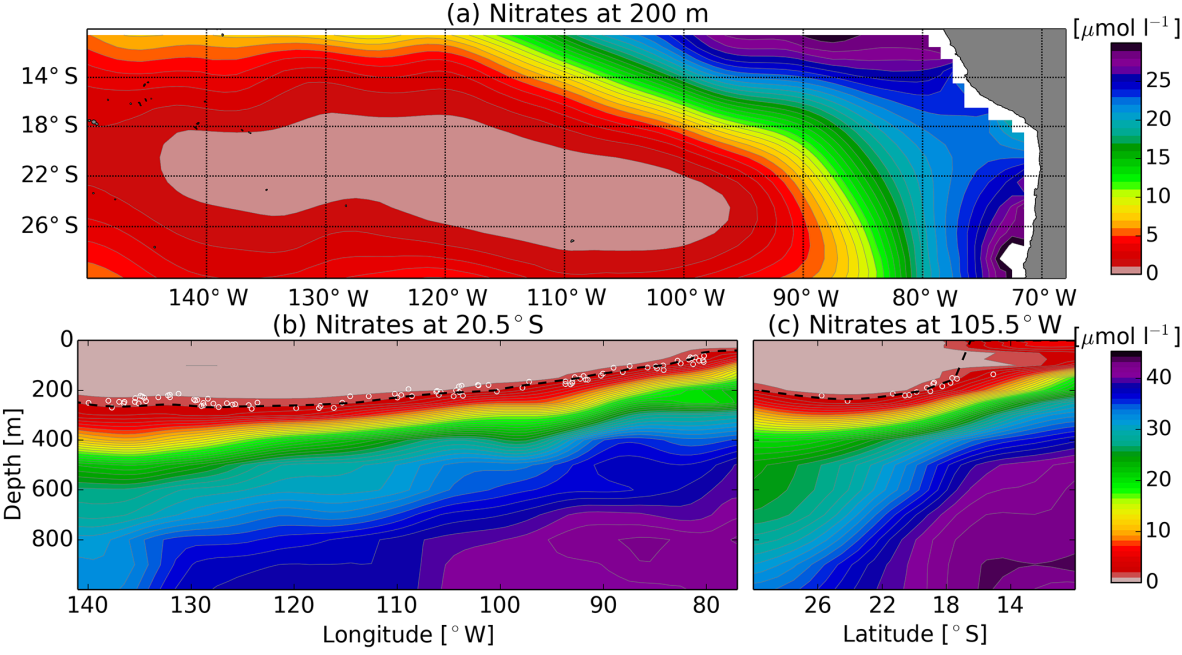

Figure 2. Climatological January nitrate from WOAPISCES in the southeast Pacific. (a) Horizontal section at $200 \mathrm{~m}$ depth, (b) vertical section at $20.5^{\circ} \mathrm{S}$ and (c) vertical section at $105.5^{\circ} \mathrm{W}$. Dashed black lines in (b) and (c) indicate the $2 \mathrm{~mol} \mathrm{~L}^{-1}$ isoline. White dots are a random sample of the simulated water parcels at their initial positions.

nitrate values near the Peru-Chile coast are associated with the coastal upwelling. In the zonal section (Fig. 2b) the uplift of the nitracline due to the coastal upwelling off the PeruChile coast is evident. In the meridional section (Fig. 2c) nitrate concentrations increase northward.

Light conditions are used in Sect. 4.2 to assess the relevance of the Lagrangian nitrate transport estimates. Surface photosynthetically active radiation $\left(E_{0}\right)$ and attenuation coefficient at $490 \mathrm{~nm}(k)$ are obtained from the MERIS monthly climatology (http://oceandata.sci.gsfc.nasa. gov/MERIS/Mapped/Monthly_Climatology $/ 9 \mathrm{~km} / \mathrm{par} /$, http://oceandata.sci.gsfc.nasa.gov/MERIS/Mapped/ Monthly_Climatology $/ 9 \mathrm{~km} / \mathrm{Kd} /$ ).

\section{Methodology}

\subsection{Computation of 3-D velocity}

Horizontal geostrophic velocities are computed at all depths $z_{i}$ through the thermal wind equations:

$$
\begin{aligned}
& u_{g}\left(z_{i}\right)=u_{g}(0)-\frac{g}{\rho f} \int_{z_{i}}^{0} \frac{\partial \rho}{\partial y} \mathrm{~d} z \\
& v_{g}\left(z_{i}\right)=v_{g}(0)+\frac{g}{\rho f} \int_{z_{i}}^{0} \frac{\partial \rho}{\partial x} \mathrm{~d} z,
\end{aligned}
$$

with the density, $\rho$, calculated from ARMOR3D temperature and salinity profiles. $f$ is the Coriolis parameter and $g$ is gravity. 

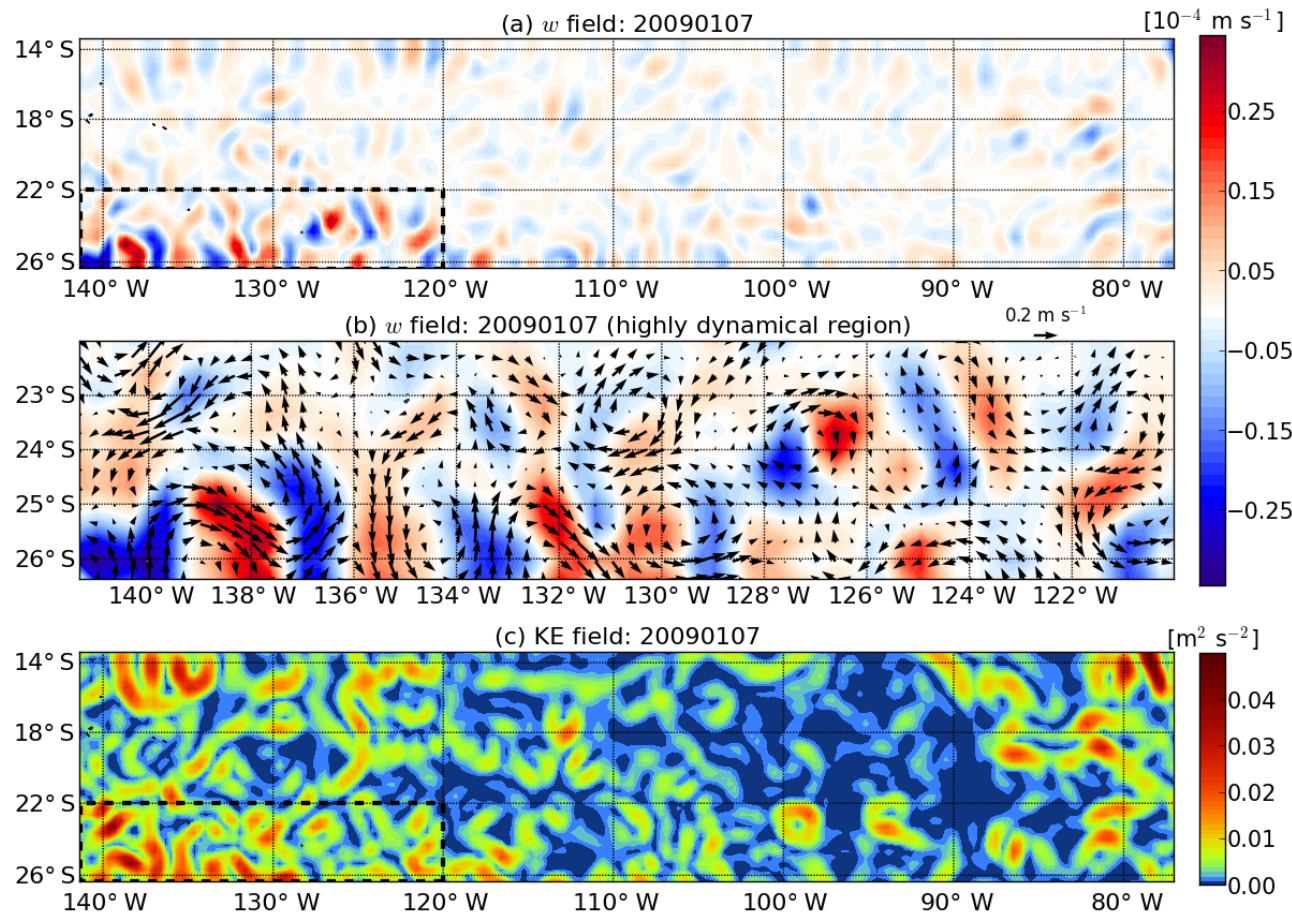

Figure 3. (a) Vertical velocity on 7 January 2009 at $200 \mathrm{~m}$ depth. Black box delimits the region of high mesoscale eddy activity. (b) Zoom of vertical velocity and horizontal geostrophic currents over the high mesoscale eddy activity region in (a). (c) Kinetic energy on 7 January 2009 at $200 \mathrm{~m}$ depth.

Vertical velocity is estimated using the quasi-geostrophic approximation by integrating the QG omega equation, presented here in its $\boldsymbol{Q}$ vector formulation (Hoskins et al., 1978; Tintoré et al., 1991; Buongiorno Nardelli et al., 2012; Pascual et al., 2015):

$N^{2} \nabla_{h}^{2} w+f^{2} \frac{\partial^{2} w}{\partial z^{2}}=2 \nabla \cdot Q$

where

$\boldsymbol{Q}=\frac{g}{\rho_{0}}\left(\frac{\partial \boldsymbol{v}_{g}}{\partial x} \cdot \nabla \rho^{\prime}, \frac{\partial \boldsymbol{v}_{g}}{\partial y} \cdot \nabla \rho^{\prime}\right)$,

where $\boldsymbol{v}_{g}$ is the geostrophic velocity vector, $\rho^{\prime}$ is the departure from the mean density profile, $N^{2}$ the Brunt-Väisälä frequency and $f$ the Coriolis parameter. In this implementation, $N^{2}$ only depends on depth. The Rossby number for mesoscale eddies in the SEP is generally less than 0.1 (Chelton et al., 2011b), hence we assume QG theory to be a good approximation for computing the vertical velocity in this region.

Following Eq. (2), vertical velocity is estimated from density stratification and the geostrophic velocity field. The computational code is derived following the QG vorticity and thermodynamic equations (Buongiorno Nardelli et al., 2012). Lateral boundaries are placed within the limits 68.4$141.3^{\circ} \mathrm{W}$ and $13.4-26.4^{\circ} \mathrm{S}$. Boundary conditions are con- structed by considering zero vertical velocity at the upper, lower and lateral boundaries.

A sensitivity analysis was carried out in order to evaluate the influence of reference level choice on the vertical velocity estimation. The choice of reference level is influential over the first hundred meters above the bottom due to the imposed boundary condition; away from the bottom the same patterns were seen for different choices of reference level (500 and $1000 \mathrm{~m}$ ). Testing the $500 \mathrm{~m}$ reference level, the vertical velocity patterns pointed to a maximum decrease in magnitude of $50 \%$. Hence, a reference level of $1000 \mathrm{~m}$ depth was chosen. Dirichlet and Neumann conditions at the lateral boundaries were tested for which we found no significant impacts on results a few points away from the boundaries.

\subsection{Lagrangian simulations}

In order to make an estimate of the potential biological impacts of the horizontal and vertical velocity components on the distribution of a limiting nutrient, in Sect. 4.2 a Lagrangian particle-tracking code is used to simulate water parcel trajectories forced by the derived ARMOR3D velocity fields. The tracking code is ROMS Offline (Roff, e.g., Capet et al., 2008; Carr et al., 2008; Mason et al., 2012). Two sets of year-long simulations were carried out for the year 2009: the first set was forced with geostrophic horizontal velocities and QG vertical velocity (UVW); for the second set the same 


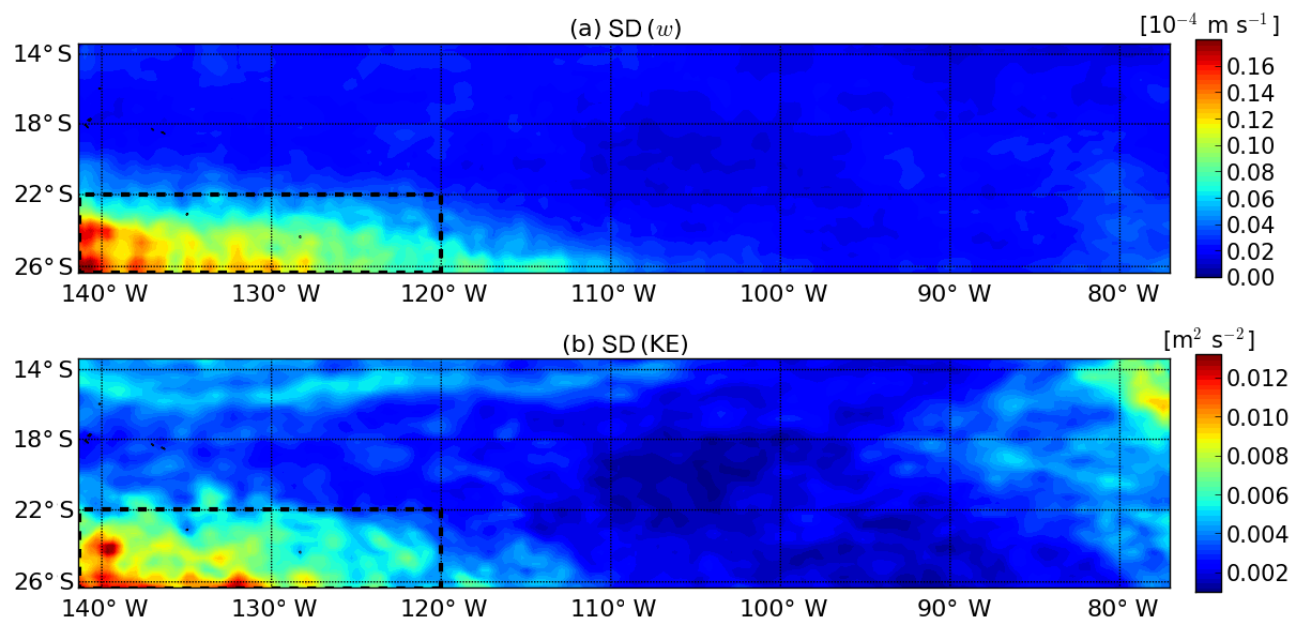

Figure 4. (a) Standard deviation of vertical velocity and (b) kinetic energy over the period 7 January 1998 to 30 December 2009 at $200 \mathrm{~m}$ depth. The discontinuous line delimits the region of high mesoscale variability.

geostrophic horizontal velocity was applied but vertical velocity was set to zero (UV). A total of 1000 passive floats were released each week over a period of 364 days (initial date 31 December 2008) at random positions within a release area determined by the nitrate depletion depth (Fig. 2). This depth was estimated for each week following Omand and Mahadevan (2015) by selecting the depth at which nitrate content is $2 \mu \mathrm{mol} \mathrm{L}{ }^{-1}$ from temporally and vertically interpolated climatological nitrate fields (WOAPISCES). Boundaries to the north, south and west are open; the eastern boundary is closed (see white box in Fig. 1). Float positions were stored every day as output of the Lagrangian simulation.

The initial nitrate concentrations for each float, $N\left(\boldsymbol{r}\left(t_{0}\right), t_{0}\right)$ with $\boldsymbol{r}(t)=(x(t), y(t), z(t))$, are interpolated in time and space from the monthly WOAPISCES climatology. In this way, the particles in each weekly release are initialized with local nutrient concentrations. The evolution of the nitrate content is then estimated along the Lagrangian tracks by considering an uptake term, $U$ and a remineralization term, $R$ :

$$
\begin{aligned}
\frac{\partial N}{\partial t} & =-U+R \\
U & =U_{0} \cdot \frac{N}{N+K_{N}} \cdot \frac{E}{E+K_{E}} \\
R & =\max \left(0, \frac{N_{\mathrm{C}}-N}{r}\right) .
\end{aligned}
$$

The maximum uptake rate, $U_{0}\left(\mu \mathrm{mol} \mathrm{L} \mathrm{L}^{-1} \mathrm{~d}^{-1}\right)$, is modulated by two Michaelis-Menten functions representing nitrate and light limitations, respectively (MacIsaac and Dugdale, 1972). The light conditions $E(\boldsymbol{r}(t), t)=$ $E_{0}((x(t), y(t), 0), t) \cdot e^{-k \cdot z(t)}$ are derived along each track by interpolation in time and space from the MERIS monthly climatology of surface Photosynthetically Active Radiation $\left(E_{0}\right)$ and attenuation coefficient at $490 \mathrm{~nm}(k)$ (Marra et al.,
2014). The values tested for the light half saturation parameter, $K_{E}=0.5,1$ and $5 \mu \mathrm{E} \mathrm{m}^{-2} \mathrm{~s}^{-1}$, are taken in the range $1-10 \%$ of the typical surface PAR intensity (MacIsaac and Dugdale, 1972). The half saturation constant for nitrate limitation is taken as $K_{N}=0.2 \mu \mathrm{mol} \mathrm{L}-1$ which is characteristic for oligotrophic marine regions (Eppley et al., 1969).

Remineralization is represented by a relaxation toward climatological nitrate values whenever the actual float $N$ content falls below $N_{\mathrm{C}}$, the climatological nitrate field (WOAPISCES). $r$ is a characteristic relaxation timescale (days). We considered the values $r$ of 5 and 10 days.

\section{Results}

\subsection{QG vertical velocity and kinetic energy from observation-based product}

A comparison between vertical velocity $(w)$ and kinetic energy (KE) computed from the ARMOR3D-derived geostrophic velocities is carried out in order to evaluate their relationship. An energetic region with high vertical velocities and mesoscale eddy activity is located in the southwest of the SEP, in both the vertical velocity (Fig. 3a) and kinetic energy (Fig. 3c) maps. This high eddy energy is related to baroclinic instabilities associated with the eastward surface STCC and the westward underlying SEC system (Qiu and Chen, 2004; Qiu et al., 2008). Figure 3c shows other regions with elevated mesoscale activity that are associated with less intense vertical velocity values. These regions are the coastal upwelling and the SECC-SEC system explained in Sect. 1.

Vertical velocity in the energetic region in the southwest is highlighted in the zoom in Fig. 3b. Intense vertical motions of the order of $2-3 \mathrm{~m} \mathrm{~d}^{-1}$ with alternating signs are located along meanders and inside eddies. The mesoscale eddies are characterized by dipole-like patterns with upwelling and 


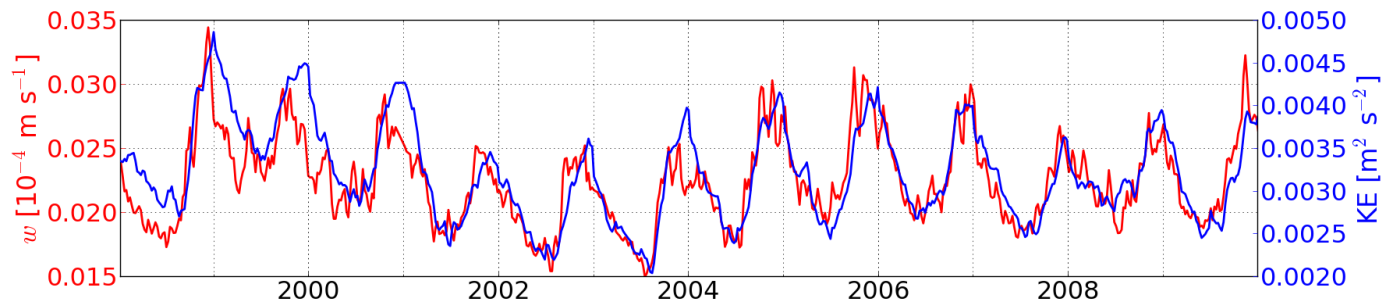

Figure 5. Time series of vertical velocity magnitude (red line) and kinetic energy (blue line) averaged over the area of study. The correlation coefficient between vertical velocity and kinetic energy is 0.84 .
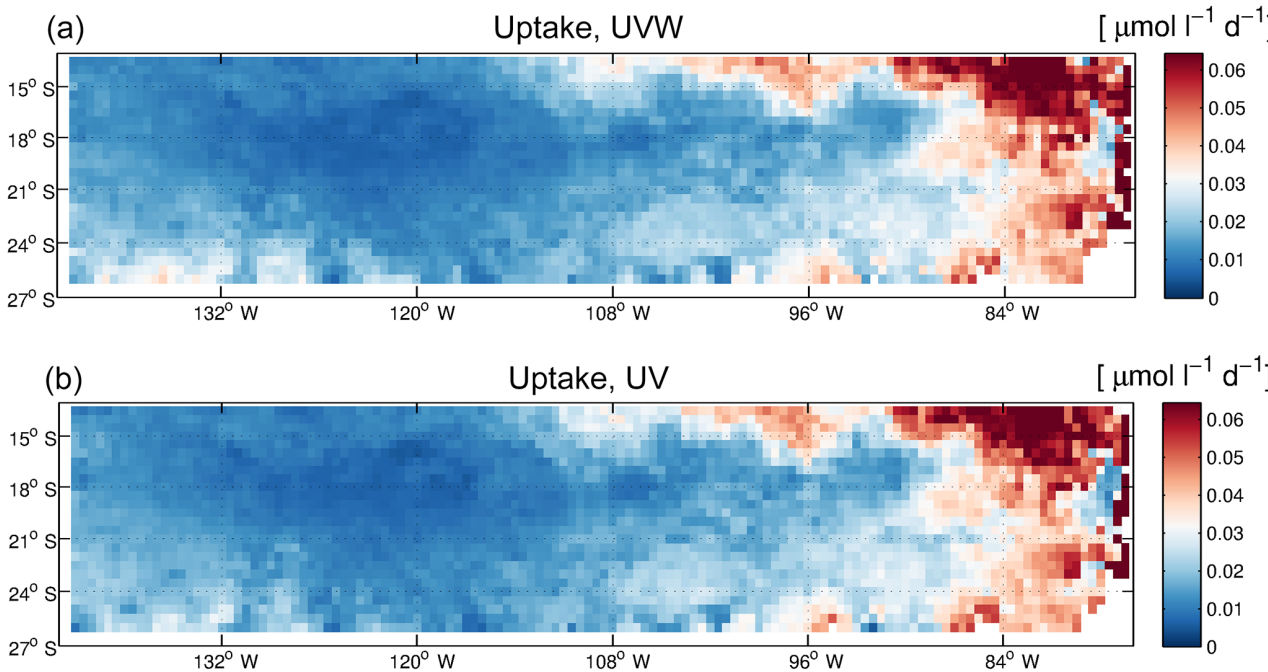

(c) Uptake, relative increase (UVW-UV)/UV

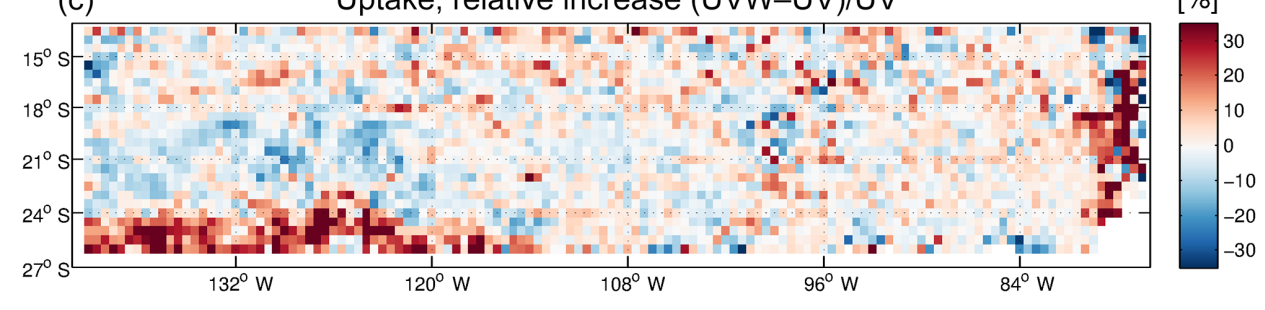

Figure 6. Nitrate uptake rates considering (a) both QG vertical velocity and geostrophic horizontal velocity (UVW); (b) only geostrophic horizontal velocity (UV); (c) relative increase of nitrate uptake rates when including vertical velocity. These fields were obtained for $r=$ 10 days, $U_{0}=0.1 \mu \mathrm{mol} \mathrm{L}^{-1} \mathrm{~d}^{-1}, K_{E}=1 \mu \mathrm{E} \mathrm{m}^{-2} \mathrm{~s}^{-1}$ and $K_{N}=0.2 \mu \mathrm{mol} \mathrm{L}^{-1}$.

downwelling cells at the eddy peripheries (e.g., $126-128^{\circ} \mathrm{W}$ and $23-25^{\circ} \mathrm{S}$ ). Vertical velocity around anticyclonic meanders (e.g., $136-139^{\circ} \mathrm{W}$ and $24-26^{\circ} \mathrm{S}$ or $120-122^{\circ} \mathrm{W}$ and $24-26^{\circ} \mathrm{S}$ ) shows the expected upwellings in the upstream and downwellings in the downstream portions of the meander crests (Woods, 1988; Bower, 1991; Pollard and Regier, 1992; Pascual et al., 2015). Similarly, downwellings and upwellings in cyclonic meanders (e.g., $137-140^{\circ} \mathrm{W}$ and $24.5-$ $26^{\circ} \mathrm{S}$ ) are located upstream and downstream of the crest, respectively.

In order to analyze the variability of $w$, the standard deviation over the period 7 January 1998 to 30 December 2009 is computed and shown in Fig. 4a; Fig. 4b shows the stan- dard deviation of the KE. The active region in the southwest of the SEP presents high temporal variability in both fields. The correlation coefficient between both fields in this region reaches 0.85 . Considering the whole area of study, the correlation coefficient is 0.79 . It should be noted that this high correlation between the two variables could not be anticipated a priori as the relationship is not linear (see Eq. 2).

Time series of spatial averages of vertical velocity magnitude and kinetic energy are shown in Fig. 5. There is clear seasonal variability in both variables, with maximums in austral summer and minimums in austral winter related to the seasonal intensification/decay of the STCC-SEC vertical shear and, in consequence, with the increase/decrease of 
(a) $K_{E}=0.5 \mu \mathrm{E} \mathrm{m}^{-2} \mathrm{~s}^{-1}$

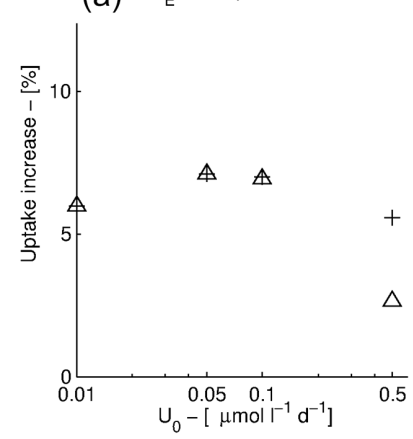

(b) $K_{E}=1 \mu \mathrm{Em}^{-2} \mathrm{~s}^{-1}$

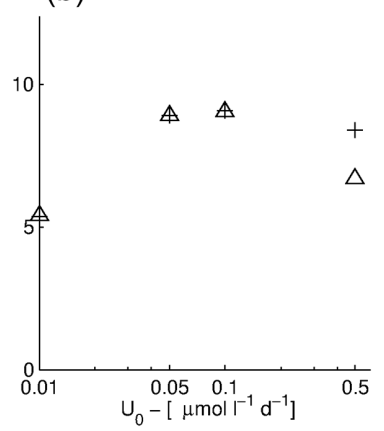

(c) $K_{E}=5 \mu \mathrm{Em}^{-2} \mathrm{~s}^{-1}$

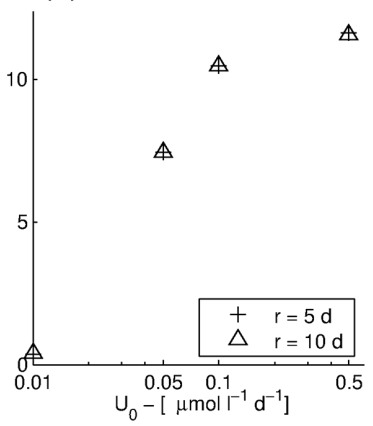

Figure 7. Average increase of nitrate uptake rates in the region of high mesoscale eddy activity (ca. $120-140^{\circ} \mathrm{W}$ and $22-26^{\circ} \mathrm{S}$ ) for different values of the uptake coefficient $U_{0}$ and relaxation timescale $r$.

baroclinic instability (Qiu et al., 2008). Interannual variability and weak variability of high frequency are also shown in these figures. When averaging over only the highly energetic region in the southwest (not shown) the tendency is similar but the magnitude is double.

\subsection{Lagrangian simulations}

In order to evaluate the potential biological impacts of the vertical velocities, we analyzed the nitrate uptake rates along the Lagrangian tracks resulting from successive weekly particle releases within the nitrate depletion depth (see Sect. 3.2). To compare nitrate uptake rates in the simulations with (UVW) and without (UV) vertical motions, we computed the median of the nitrate uptake terms in bins of $0.5^{\circ} \times 0.5^{\circ}$ over the full annual simulations. The deeper particle tracks, for which uptake terms were lower than $0.001\left(\mu \mathrm{mol} \mathrm{L}^{-1} \mathrm{~d}^{-1}\right)$, were disregarded in these computations. As expected, nitrate uptake rates (Fig. 6) are higher in the northeastern upwelling region. Intermediate uptake values can also be seen in the region of high mesoscale activity (ca. $120-140^{\circ} \mathrm{W}$ and $22-$ $26^{\circ} \mathrm{S}$ ). While the restricted resolved vertical velocities leave the overall pattern of nitrate uptake unchanged, local nitrate uptake increases reach up to $30 \%$ in the region characterized by low uptake rates and high mesoscale activity (Fig. 6c).

The simplified nutrient model considered here is not suitable for a detailed study of the dynamics of nitrate, in particular as it does not consider planktonic biomass and diversity. However, we tested the sensitivity of the results to the $U_{0}, r$ and $K_{E}$ parameters. In Fig. 7 we show that spatially averaged increases in uptake rates over the region of high mesoscale activity vary between 0.4 and $11.6 \%$, with an average of $6.5 \%$ for the considered range of parameter values. Larger increases are observed in the cases with high maximum uptake rates and strong light limitation.

\section{Discussion and Conclusions}

This paper analyses vertical velocities associated with QG dynamics as derived through an innovative approach that uses the ARMOR3D global observation-based product. Weekly horizontal geostrophic velocity and QG vertical velocity are computed from ARMOR3D temperature and salinity in the southeast Pacific. We analyze the QG vertical velocity in order to understand its distribution. The southwest of the SEP has relatively high mesoscale activity with vertical velocities exceeding $2 \mathrm{~m} \mathrm{~d}^{-1}$, which is on the order of $10^{-4}$ times the horizontal velocity. Vertical velocity and kinetic energy in the SEP have similar and intense seasonal variability with maximums in austral summer (November-December), which suggests that these quantities are mostly influenced by the seasonal modulation of STCC-SEC vertical shear (Qiu and Chen, 2004; Qiu et al., 2008).

Despite their relatively small magnitudes, vertical motions may have an important impact on the introduction of nutrients into the euphotic layer in areas with pre-existing vertical gradients of nutrients and hence can be considered influential on marine ecosystem variability. Two year-long Lagrangian simulations are forced with 3-D velocity fields. The first is forced by 3-D geostrophic velocities and QG vertical velocity in order to evaluate their combined contribution to rates of nitrate uptake along the tracks. The second is forced with the same 3-D geostrophic velocities and zero vertical velocity in order to evaluate the horizontal velocity contribution to the nitrate uptake. The Lagrangian experiments enable an examination of nitrate uptake rates under varying light conditions within the euphotic layer. This analysis reveals that, in regions with low rates of nitrate uptake, vertical motions associated with high mesoscale activity may be responsible for local increases in these uptake rates of up to $30 \%$. We caution that the nitrate model used is simple and that the outcomes are sensitive to the chosen values of maximum nitrogen uptake rate $\left(U_{0}\right)$ and light half-saturation parameter $\left(K_{E}\right)$. Nevertheless, these results are indicative of the importance that mesoscale vertical motions have on sustaining pri- 
mary productivity in the oligotrophic regions of ocean interiors.

Although we only analyze the (large) mesoscale vertical velocity, the importance of submesoscale features on vertical tracer dispersion has been shown by Klein and Lapeyre (2009). Accordingly, the vertical velocity contribution estimated here can be considered an underestimation of the real vertical velocity contribution. Fine-resolution satellite observations can help to better evaluate the impact of vertical motions on nutrient redistribution. The wide-swath SWOT altimeter will allow unique observations in the $15-100 \mathrm{~km}$ range of wavelength scales when it comes online in the next decade (Fu and Ferrari, 2008).

\section{Data availability}

Data and codes are available from the first author upon request.

Acknowledgements. This work has been carried out as part of the E-MOTION (CTM2012-31014) project funded by the Spanish National Research Program. Additional funding from the local government of the Balearic Islands (CAIB-51/2011 grant) is also acknowledged. Bàrbara Barceló-Llull is supported by a doctoral grant from the Spanish National Research Program associated with the PUMP (CTM2012-33355) project. Evan Mason is supported by a post-doctoral grant from the Conselleria d'Educació, Cultura i Universitats del Govern de les Illes Balears (Mallorca, Spain) and the European Social Fund. Arthur Capet is funded by the European Union under FP7- People-Co-funding of Regional, National and International Programmes, GA no. 600407. The ARMOR3D data set was produced by CLS with support from the MyOcean project (EU no. P7-SPACE-2007-1 grant agreement 218812). Nitrate data were extracted from the WOAPISCES biogeochemical climatology (http://www.romsagrif.org/).

Edited by: M. Hecht

Reviewed by: P. Gaube and X. Capet

\section{References}

Benítez-Barrios, V., Pelegrí, J. L., Hernández-Guerra, A., Lwiza, K. M. M., Gomis, D., Vélez-Belchí, P., and Hernández-León, S.: Three-dimensional circulation in the NW Africa coastal transition zone, Prog. Oceanogr., 91, 516-533, 2011.

Bower, A. S.: A simple kinematic mechanism for mixing fluid parcels across a meandering jet, J. Phys. Oceanogr., 21, 173-180, 1991.

Brink, K. H. and Robinson, A. R. (EDS.): The Sea, Volume 11: The Global Coastal Ocean: Regional Studies and Syntheses, Harvard University Press, 2005.

Brown, S. L., Landry, M. R., Selph, K. E., Jin Yang, E., Rii, Y. M., and Bidigare, R. R.: Diatoms in the desert: Plankton community response to a mesoscale eddy in the subtropical North Pacific, Deep-Sea Res., 55, 1321-1333, 2008.
Buongiorno Nardelli, B.: Vortex waves and vertical motion in a mesoscale cyclonic eddy, J. Geophys. Res.-Ocean., 118, 56095624, 2013.

Buongiorno Nardelli, B., Guinehut, S., Pascual, A., Drillet, Y., Ruiz, S., and Mulet, S.: Towards high resolution mapping of 3-D mesoscale dynamics from observations, Ocean Sci., 8, 885-901, doi:10.5194/os-8-885-2012, 2012.

Capet, A., Mason, E., Rossi, V., Troupin, C., Faugère, Y., Pujol, I., and Pascual, A.: Implications of refined altimetry on estimates of mesoscale activity and eddy-driven offshore transport in the Eastern Boundary Upwelling Systems, Geophys. Res. Lett., 41, 7602-7610, 2014.

Capet, X. J., Campos, E. J., and Paiva, A. M.: Submesoscale activity over the Argentinian shelf, Geophys. Res. Lett., 35, L15605, doi:10.1029/2008GL034736, 2008.

Carr, S. D., Capet, X. J., McWilliams, J. C., Pennington, J. T., and Chavez, F. P.: The influence of diel vertical migration on zooplankton transport and recruitment in an upwelling region: estimates from a coupled behavioral-physical model, Fish. Oceanogr., 17, 1-15, 2008.

Chelton, D. B., Gaube, P., Schlax, M. G., Early, J. J., and Samelson, R. M.: The Influence of Nonlinear Mesoscale Eddies on NearSurface Oceanic Chlorophyll, Science, 334, 328-332, 2011 a.

Chelton, D. B., Schlax, M. A., and Samelson, R. M.: Global observations of nonlinear mesoscale eddies, Prog. Oceanogr., 91, 167-216, $2011 b$.

Dibarboure, G., Pujol, M.-I. ., Briol, F., Le Traon, P.-Y., Larnicol, G., Picot, N., Mertz, F., and Ablain, M.: Jason-2 in DUACS: Updated system description, first tandem results and impact on processing and products, Mar. Geod., 34, 214-241, 2011.

Ducet, N., Le Traon, P.-Y., and Reverdin, G.: Global high-resolution mapping of ocean circulation from TOPEX/Poseidon and ERS-1 and -2, J. Geophys. Res., 105, 19477-19498, 2000.

Eppley, R. W., Rogers, J. N., and McCarthy, J. J.: Half-saturation constants for uptake of nitrate and ammonium by marine phytoplankton, Limnol. Oceanogr., 14, 912-920, 1969.

Fu, L.-L. and Ferrari, R.: Observing Oceanic Submesoscale Processes From Space, Eos Trans. AGU, 89, 488-488, 2008.

Gaube, P., Chelton, D. B., Strutton, P. G., and Behrenfeld, M. J.: Satellite observations of chlorophyll, phytoplankton biomass, and Ekman pumping in nonlinear mesoscale eddies, J. Geophys. Res., 118, 6349-6370, 2013.

Gaube, P., Chelton, D. B., Samelson, R. M., Schlax, M. G., and O'neill, L. W.: Satellite Observations of Mesoscale EddyInduced Ekman Pumping, J. Phys. Oceanogr., 45, 104-132, 2015.

Guinehut, S., Dhomps, A.-L., Larnicol, G., and Le Traon, P.Y.: High resolution 3-D temperature and salinity fields derived from in situ and satellite observations, Ocean Sci., 8, 845-857, doi:10.5194/os-8-845-2012, 2012.

Hoskins, B. J., Draghici, I., and Davies, H. C.: A new look at the $\omega$-equation, Q. J. R. Met. Soc., 104, 31-38, 1978.

Imawaki, S., Bower, A. S., Beal, L., and Qiu, B.: Western Boundary Currents, chap. 13, in: Ocean Circulation and Climate A 21st Century Perspective, edited by: Siedler, G., Griffies, S. M., Gould, J., and Church, J. A., Academic Press, 103, 305-338, 2013. 
Klein, P. and Lapeyre, G.: The Oceanic Vertical Pump Induced by Mesoscale and Submesoscale Turbulence, Annu. Rev. Mar. Sci., 1, 351-375, 2009.

Lathuiliere, C., Levy, M., and Echevin, V.: Impact of eddy-driven vertical fluxes on phytoplankton abundance in the euphotic layer, J. Plank. Res., 33, 827-831, 2011.

MacIsaac, J. and Dugdale, R.: Interactions of light and inorganic nitrogen in controlling nitrogen uptake in the sea, Deep-Sea Res.Oceanogr. Abstracts, Elsevier, 19, 209-232, 1972.

Mahadevan, A.: Eddy effects on biogeochemistry, Nature, 506, 168-169, 2014

Mahadevan, A., D’Asaro, E., Lee, C., and Perry, M. J.: Eddydriven stratification initiates North Atlantic spring phytoplankton blooms, Science, 336, 54-58, 2012.

Marra, J. F., Lance, V. P., Vaillancourt, R. D., and Hargreaves, B. R.: Resolving the ocean's euphotic zone, Deep-Sea Res. Pt. I, 83, 45-50, 2014.

Martin, A. P. and Richards, K. J.: Mechanisms for vertical nutrient transport within a North Atlantic mesoscale eddy, Deep-Sea Res. Pt. II, 48, 757-773, 2001.

Mason, E., Colas, F., and Pelegrí, J. L.: A Lagrangian study tracing water parcel origins in the Canary Upwelling System, Sci. Mar., 76, 79-94, 2012.

McGillicuddy, D. J., Robinson, A. R., Siegel, D. A., Jannasch, H. W., Johnson, R., Dickey, T. D., McNeil, J., Michaels, A. F., and Knap, A. H.: Influence of mesoscale eddies on new production in the Sargasso Sea, Nature, 394, 263-266, 1998.

McGillicuddy, D. J., Anderson, L. A., Bates, N. R., Bibby, T., Buesseler, K. O., Carlson, C. A., Davis, C. S., Ewart, C., Falkowski, P. G., Goldthwait, S. A., Hansell, D. A., Jenkins, W. J., Johnson, R., Kosnyrev, V. K., Ledwell, J. R., Li, Q. P., Siegel, D. A., and Steinberg, D. K.: Eddy Wind interactions stimulate extraordinary mid-ocean plankton blooms, Science, 316, 1021-1026, 2007.

Morel, A., Claustre, H., and Gentili, B.: The most oligotrophic subtropical zones of the global ocean: similarities and differences in terms of chlorophyll and yellow substance, Biogeosciences, 7, 3139-3151, doi:10.5194/bg-7-3139-2010, 2010.

Mulet, S., Rio, M.-H., Mignot, A., Guinehut, S., and Morrow, R.: A new estimate of the global 3D geostrophic ocean circulation based on satellite data and in-situ measurements, Deep-Sea Res. Pt. II, 77-80, 70-81, 2012.
Omand, M. M. and Mahadevan, A.: The shape of the oceanic nitracline, Biogeosciences, 12, 3273-3287, doi:10.5194/bg-12-32732015, 2015.

Pascual, A., Faugère, Y., Larnicol, G., and Le Traon, P.-Y.: Improved description of the ocean mesoscale variability by combining four satellite altimeters, Geophys. Res. Lett., 33, L02611, doi:10.1029/2005GL024633, 2006.

Pascual, A., Ruiz, S., Buongiorno Nardelli, B., Guinehut, S., Iudicone, D., and Tintoré, J.: Net primary production in the Gulf Stream sustained by quasi-geostrophic vertical exchanges, Geophys. Res. Lett., 42, 441-449, 2015.

Penven, P., Marchesiello, P., Debreu, L., and Lefèvre, J.: Software tools for pre- and post-processing of oceanic regional simulations, Environ. Modell. Softw., 23, 660-662, 2008.

Pollard, R. T. and Regier, L. A.: Vorticity and Vertical Circulation at an Ocean Front, J. Phys. Oceanogr., 22, 609-625, 1992.

Qiu, B. and Chen, S.: Seasonal modulations in the Eddy Field of the South Pacific Ocean, J. Phys. Oceanogr., 34, 1515-1527, 2004.

Qiu, B., Scott, R. B., and Chen, S.: Length Scales of Eddy Generation and Nonlinear Evolution of the Seasonally Modulated South Pacific Subtropical Countercurrent, J. Phys. Oceanogr., 38, 1515-1528, 2008.

Ras, J., Claustre, H., and Uitz, J.: Spatial variability of phytoplankton pigment distributions in the Subtropical South Pacific Ocean: comparison between in situ and predicted data, Biogeosciences, 5, 353-369, doi:10.5194/bg-5-353-2008, 2008.

Siegel, D. A., McGillicuddy Jr., D. J., and Fields, E. A.: Mesoscale eddies, satellite altimetry, and new production in the Sargasso Sea, J. Geophys. Res.-Ocean., 104, 13359-13379, 1999.

Strub, P. T., Combes, V., Shillington, F. A., and Pizarro, O.: Currents and Processes along the Eastern Boundaries, chap. 14, in: Ocean Circulation and Climate A - 21st Century Perspective, edited by: Siedler, G., Griffies, S. M., Gould, J., and Church, J. A., Academic Press, 103, 339-384, 2013.

Tintoré, J., Gomis, D., Alonso, S., and Parrilla, G.: Mesoscale Dynamics and Vertical Motion in the Alborán Sea, J. Phys. Oceanogr., 21, 811-823, 1991.

Woods, J.: Toward a Theory on Biological-Physical Interactions in the World Ocean, Scale Upwelling and Primary Production, Springer Netherlands, 7-38, 1988. 